\title{
Wide excision and reconstruction surgery using NVFG for giant cell tumor of the right proximal radius campanacci 3
}

\begin{abstract}
Giant Cell Tumors, commonly known as GCT is a type of typically benign, potentially malignant tumors. GCT have a tendency for reccurence and often extends to the articular subchondral bone and cartilage. GCT of the proximal radius is rare case. the joint and its capsule are rarely invaded. The standard mode of treatment for GCT is surgical resection, of which the key to ensuring an adequate surgical treatment is complete tumor excision and achieving adequate lesion exposure..We reported a case series from three patients with Giant cell tumor (GCT) of the proximal radius. Two of the patients have GCT of the left proximal radius, and the other one on the right proximal radius. Patient mostly presented with chief complain pain on the elbow and fore arm region. Radiographic examination showed a primary bone tumor of the proximal radius. MRI provided excellent depiction in suggesting the diagnosis of cutaneous GCT campanacci 3, which was later, affirmed by biopsy. All Patient underwent successful wide excision and non-vascularized fibular graft reconstruction. The limb salvage procedure consists elbow joint excision and NVFG reconstruction. During 1 year follow up post-operative period, there was no major event observed. The pain sensation was diminished, and the ROM elbow back to normal limit because it was pain free. The GCT usually appears as an eccentric and expansile lesion located on the epiphyseal area, oftenly characterized with its signature soap-bubble appearance.MRI is useful to assess extracortical spread and intramedullary extension. Among the numerous choice of surgical approach, reconstruction surgery is preferred, while curettage is often performed with a combination with bone cement and/or bone graft..Wide resection of proximal radius and reconstruction with non-vascularized fibular graft is might be beneficial in retaining the elbow function as well as achieving satisfactory ROM and strength. It is also a viable option, as it provides good pain relief with lower complication rates.
\end{abstract}

Keywords: giant cell, campanacci 3, wide excision, reconstruction, proximal radius, nonvascularized fibular graft
Volume 9 Issue 5 - 2019

\author{
Yogi Prabowo, Irsan Abubakar, I Wayan Arya \\ Mahendra Karda, Eugene Dionysios, Juniarto \\ Jaya Pangestu
}

Department of Orthopaedic and Traumatology, Cipto

Mangunkusumo Hospital, Indonesia

Correspondence: Irsan Abubakar, Department of Orthopaedic and Traumatology, Cipto Mangunkusumo Hospital, Indonesia, Email dr.irsan.abubakar88@gmail.com

Received: September 30, 2019 | Published: October 07, 2019

\section{Introduction}

Giant Cell tumors, also widely abbreviated as GCT, is a type of benign, potentially aggressive tumor. It is a fairly common occurrence, representing around $5 \%$ of all primary bone tumors. ${ }^{1,2}$ GCT is often linked with significant disruption of bone structure, which could be severely damaging in peri-articular locations. ${ }^{2}$ For tumor that is considered benign, GCT is highly recurrent and have a high potential for metastasis; $1-9 \%$ of GCT patients are presented with metastasis, and some studies have correlated this with local recurrence and the aggressive tumor type. ${ }^{3}$ GCT most commonly occurs due into the 3 rd decade of life, with around $80 \%$ of GCT cases being found in patients of 20 to 50 years of age. Less than 3\% of GCT cases are found on patient less than 14 years old, and $13 \%$ of cases occurring in patients over the age of $50 .^{4}$

The majority of GCT occurs at the epiphyseal location, often extending to the articular subchondral bone or even the cartilage, although the joint itself and its capsule are very rarely involved. In some very rare cases, GCT may occur in patients with immature skeleton, with the lesion being found mostly on the metaphysis. ${ }^{5}$ The most common locations where GCT could occur is distal femur, proxima tibia, distal radius, and sacrum in consecutive order. Around half of all GCT cases are found in the knee region, the rest are evenly distributed among the fiular head, proximal femur, and proximal humerus, with the least common predilection site being the pelvis. ${ }^{6}$

Disturbance of daily activites and mechanical insufficiency is most commonly caused by pain as a symptom resulting from bone tissue destruction. A soft tissue lump can be observed as a result of cortical destruction and tumor progression extending from the bone. As GCT is commonly found close to the joint, ROM decrease, joint effusion, and synovitis are usually present. Approximately $12 \%$ of GCT patients present with pathological fracture. This might indicate the aggressiveness of disease, with an increasing risk of local recurrence and metastasis. ${ }^{78}$ GCT is generally classified with the Enneking Classification as well as Campanacci classification, which monitors its radiographic appearance. They described three stages of classification that correlate with local aggressiveness of the tumor and risk of local recurrence, they are Stage I (latent), Stage II (active), Stage III (aggressive).

Campanacci first classified GCT lesions based on their radiological appearance; all GCT cases, primary and recurrent, are assessed by their radiological appearance and were designated with the own classified grades; Grade I, II, II with fracture, and III. Grade I tumor is characterized by a well-marginated border, a thin rim of mature bone, and an intact cortex, while grade II tumor has a relatively well-defined borders with radiologically thin cortex and rim. Fractures are graded separately whenever it is present in Grade II Tumors. Grade III are 
characterized with fuzzy borders that is highly suggestive of rapid and infiltrative growth into soft tissues.

The treatment mode of choice for GCT is surgical resection. Most of GCT cases are benign and is predilected in the proximity of joints, therefore, several studies favor an intralesional approach that aims to salvage the anatomy of the bone and joint instead of wide resection. ${ }^{9,10}$ Other studies suggests that wide resection is linked to the decreased number of reccurence, increasing the reccurence free survival rate from $84 \%$ to $100 \%$ when compared to other procedures such as intralesional curettage. ${ }^{11}$ This procedure, however, is associated with a higher degree of surgical complications and disability; most cases ends up being surgically rconstructed. ${ }^{11,12}$ Intralesional curettage with autograft reconstruction have been utilized to achieve local control without compromising joint function; the cavity of the excised tumor is packed with morelized iliac corticocancellous bone. This procedure have a reccurence rate of about $60 \% .^{10}$

Adequate lesion exposure should be achieved to ensure complete excision of the tumor. ${ }^{13}$ This could be achieved by making a cortical window to access the tumor, as to avoid having to perform unnecessary curettage under overhanging bone ridges. This could be done by using several instruments; headlamp and dental mirror, with the combined use of multiple angled curretes could pinpoint the exact location of residual tumor mass that may develop into reccurence. The use of a high-powered burr could break the bony ridges, expanding the curettage. Additionally, the use of a pulsating jet lavage at the end of curettage could help expose the raw surface of the cancellous bone, as well as irrigate the tissues from residual tumor cells. ${ }^{14}$

The reccurence rate of curettage followed by bone grafting is around $25-50 \%$, which leads to the development of more advanced and novel methods of surgery, such as the use of chemical adjuvants (liquid nitrogen, phenol, hydrogen peroxide), as well as chemotherapy and radiation therapy, of which the latter had been associated with the development of malignant tissue from the original tumor but have been making advanced leaps in patient safety with new, different radiotherapeutic modalities. . $^{16,17,18}$

Local adjuvant therapy has shown to be useful in controlling recurrence rates., although recent literatures have also discussed that an adequate removal of tumor tissues have more significance in reducing reccurence rate than the use of adjuvants and filling agents. ${ }^{19}$

According to Trieb15, the local recurrence rate of long bone GCT treated with or without phenol is without significant difference. Prosser ${ }^{20}$ stated that primary curettage for intraosseous GCT is should be performed without the addition adjuvant treatment or filling agents. Reconstruction of the defect left after the initial removal of tumor

Table I Three subjects with GCT of the elbow tissues poses an enormous challenge: small gaps re often left alone to be filled with blood clot, which will eventually ossify to form new bone, while larger gaps are usually filled with bone cement or bone graft.

In this case series we presented three cases of proximal radius GCT that were treated by wide excision and non vascularized fibular graft.

\section{Method}

We collected all data of all patients with GCT in outpatient clinic treated with wide excision and non-vascularized fibular graft (NVFG). The study was conducted in our institution and a computerized search was used to search the operative reports of those patients. Information was obtained through patient follow-up and medical record. The diagnosis of GCT was obtained by careful history taking, physical examination, radiologic examination (radiography and MRI), and biopsy for histopathological confirmation. After surgery, patients were followed up, pain and range of movement were assessed.

\section{Surgical procedure}

Before surgery, routinely performed preoperative bowel preparations, preoperative ureteric catheterization, application of an intravenous catheter for post operative analgesia were essential for surgical management. We also used rapid infusion system in cases in which major blood loss might occur. The surgical procedures were all performed by one Oncological Orthopaedic specialist.

We performed wide excision and reconstruction using nonvascularized fibular graft for the patients. The tumor was easily demarcated. After the tumour was exposed and the radial nerve is preserved, tumor was excised widely. Then we evaluated the margin of the wound, did proximal radius osteotomy. After tumor was removed, we did allograft transplantation of non vascularized fibula in order to reconstruct the gap and fixed using plate, screw, and mesh. We used small implant DCP with 10 holes or recon plate 3.5 . Finally we decided to perform primary

\section{Result}

We found three subjects with GCT of the elbow (Table 1). Two subjects were male with the age of 30 and 31 years old, other subject was a 19 years old female. The patients came to the outpatient clinic with the symptoms of pain. On the physical examination we found deformity enlarging mass, and limited range of movement (ROM) (Figure 2). Anteroposterior and lateral radiographic findings were osteolytic mass at proximal radius that expanded to metaphyseal and diaphyseal region. The MRI finding was high intense mass (Figure 3) (Figure 4).

\begin{tabular}{|c|c|c|c|c|c|c|c|}
\hline No & Sex & $\begin{array}{l}\text { Age } \\
(y \cdot 0)\end{array}$ & Malignancy & $\begin{array}{l}\text { Chief } \\
\text { complaints }\end{array}$ & $\begin{array}{l}\text { Diagnosis } \\
\text { (histopathology) }\end{array}$ & $\begin{array}{l}\text { Type of } \\
\text { reconstruction }\end{array}$ & $\begin{array}{l}\text { Functional } \\
\text { outcome }\end{array}$ \\
\hline I & $M$ & 30 & Benign & $\begin{array}{l}\text { Pain on the left elbow } \\
\text { since } 3 \text { years ago, } \\
\text { ROM was limited }\end{array}$ & $\begin{array}{l}\text { GCT of left Proximal } \\
\text { Radius Campanacci } 3\end{array}$ & $\begin{array}{l}\text { Wide excision and } \\
\text { reconstruction using } \\
\text { NVFG }\end{array}$ & $\begin{array}{l}\text { Pain free with } \\
\text { increasing elbow } \\
\text { ROM }\end{array}$ \\
\hline 2 & $M$ & 31 & Benign & $\begin{array}{l}\text { Pain on right elbow } \\
\text { since I year ago }\end{array}$ & $\begin{array}{l}\text { GCT of right Proximal } \\
\text { Radius Campanacci } 3\end{array}$ & $\begin{array}{l}\text { Wide excision and } \\
\text { reconstruction using } \\
\text { NVFG }\end{array}$ & Pain free \\
\hline 3. & $\mathrm{~F}$ & 19 & Benign & $\begin{array}{l}\text { Pain on the left } \\
\text { forearm since } 9 \\
\text { months ago, ROM was } \\
\text { limited }\end{array}$ & $\begin{array}{l}\text { GCT of left Proximal } \\
\text { Radius Campanacci } 3\end{array}$ & $\begin{array}{l}\text { Wide excision and } \\
\text { reconstruction using } \\
\text { NVFG }\end{array}$ & $\begin{array}{l}\text { Pain free with } \\
\text { increasing elbow } \\
\text { ROM }\end{array}$ \\
\hline
\end{tabular}



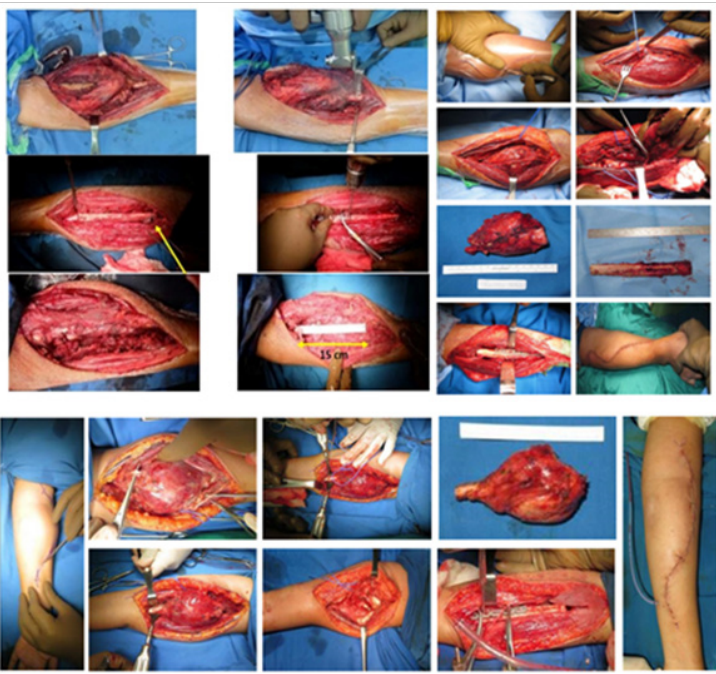

Figure I The surgical procedure, which includes wide excision and reconstruction using non-vascularized fibular graft was performed.
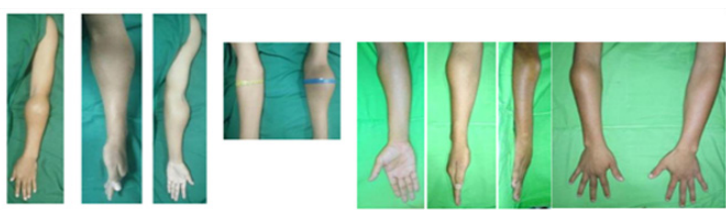

Figure 2 Physical examination of the patients showed lump around the elbow.

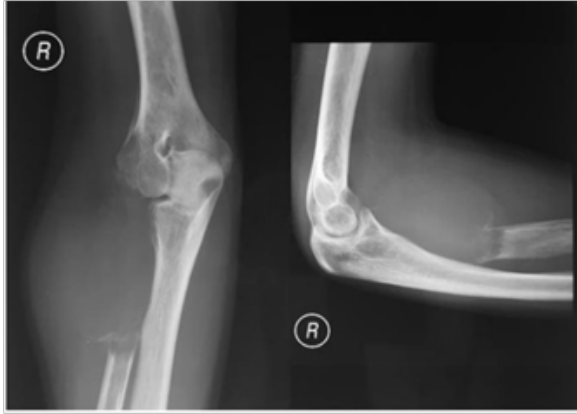

Figure 3 Radiographic findings show osteolytic mass at proximal radius that expanded to metaphyseal and diaphyseal region.

At 1 year follow up, the first patient had good quadriceps function with no evidence of recurrence or metastasis. There were no complaints of pain or instability at elbow or wrist. The patient was already able to do daily activities without limitation such as tie shoes, manage toileting and comb hair. During our physical examination, all active range of motion, whether it is flexion, extension, pronation or supination, is normal. It wasn't affected by pain at all. Grip strength was good, the patient felt it as strong as before the surgery.

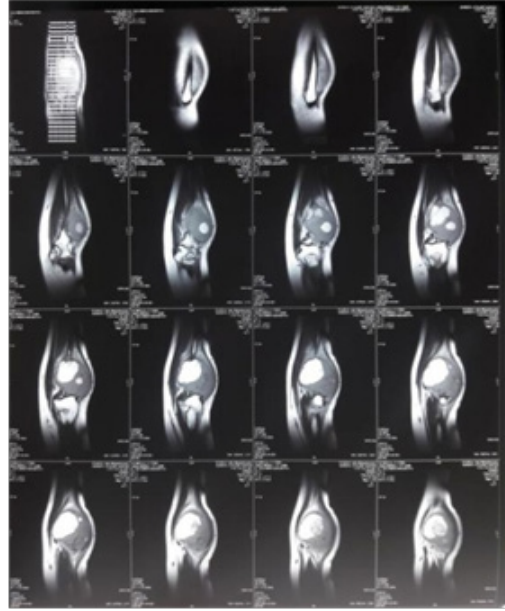

Figure $4 \mathrm{MRI}$ finding show a high intense mass.

Wide excision and non vascularized fibular graft reconstruction method result was good on three cases described above. The outcome were good on all cases, No impairment of elbow joint motion observed on all three cases in one month period after surgery because there were no lump and pain sensation post operatively. There were no evidence of infection and nerves disorder (Figure 5).
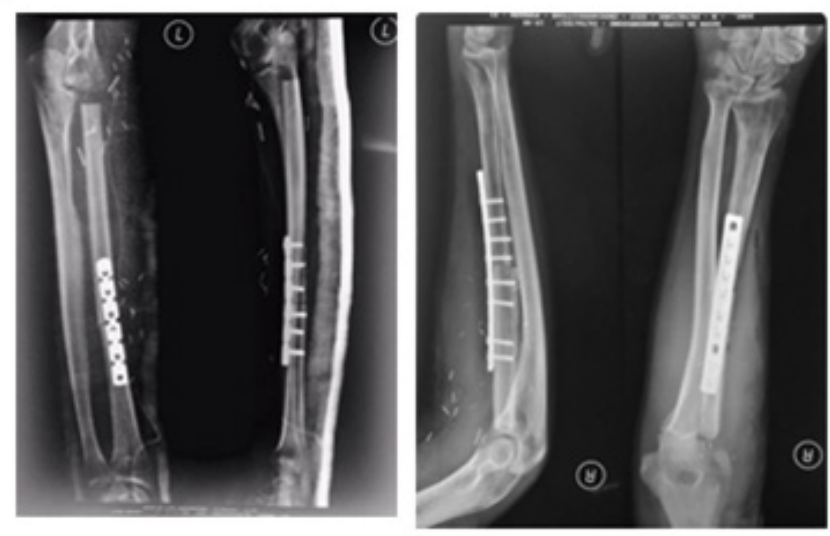

Figure 5 postoperative radiographic examination.

There were no signs of recurrence from 1-year follow up of the second patient. He was satisfied with his treatment because he felt no disability. Range of elbow motion was increased, with full pronation and better supination compared to pre-operative condition. Grip strength was good and no complain of pain even when we resisted the motion while examining the muscle strength. Eat with utensil, turn a key, throw a ball, rise from chair pushing with arm and the others daily activities could be done without ease (Figure 6) (Figure 7).
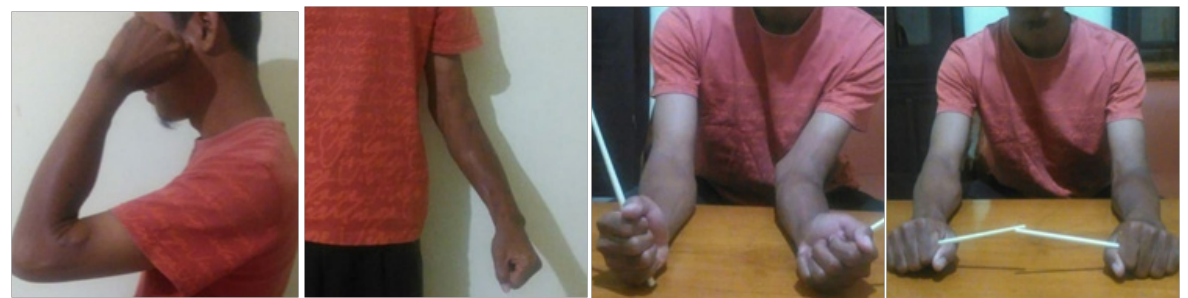

Figure 6 Functional outcome of Case I after I-year follow-up. 

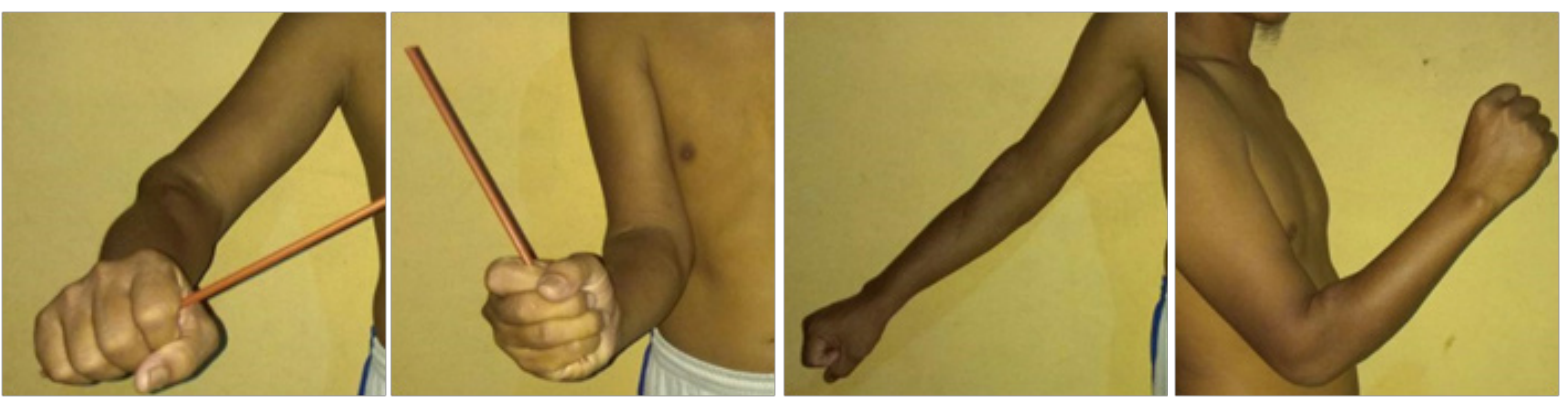

Figure 7 Functional outcome of Case 2 after I-year follow-up.

\section{Discussion}

GCT of bone can cause pain and effusion and decrease joint motion if its growth is big enough near the joint (Figure 8). In some cases, the common clinical manifestation is pathological fracture. This tumor is mainly benign, locally invasive, but has a very small potential to metastasize to the lungs. The typical bone GCT shows up in a soap-bubble appearance, showing an eccentric and expansile lesion around the epiphyseal region. Spread outside of the cortex and extension to the intramedullary of the tumor is best assessed with MRI. Histopathological specimens usually show multinucleated giant cells with up to 100 nuclei with prominent nucleoli. In contrast to the benign osteoclast-type giant cells, surrounding cells of the GCT have nuclei with similar characteristics to those in the giant cells. ${ }^{21}$
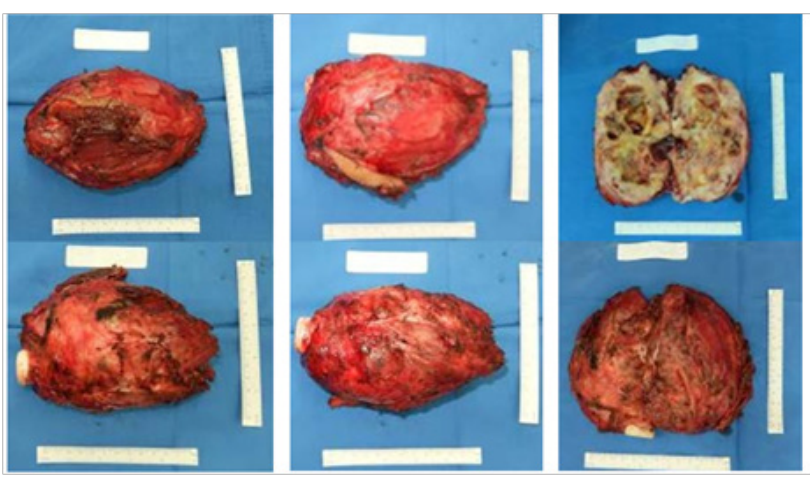

Figure 8 Gross pathological finding of GCT.

The choice of treatment can affect the recurrence rate of GCT. If the lesion is limited to the cortex, local curettage is usually indicated. However, this procedure has a relatively high local recurrence rate. One of the limitations of curettage procedure is the size of the lesion. If the tumor has expanded beyond the cortex, resection is the treatment of choice. Wide lesion resection may produce a defect that requires future reconstruction. The reconstruction method can be arthroplasty or arthrodesis using vascularized or non vascularized bone grafts. Bone grafts can be taken from tibia, proximal fibula, iliac crest, or distal part of ulna. ${ }^{22}$

A study by Gokaraju et al. found a good midterm results in a case series (five patients of proximal radius GCT) with metal proximal radial endoprosthesis instead of fibular grafting. This preocedure resulted with satisfactory stability and functional score. Despite of many advantages, prosthetic radial head replacement is still not established as the routine procedure. Cost is one of the important factors regarding this consideration. ${ }^{23,25}$

Fibular transfer is the most suitable choice for more than $6 \mathrm{~cm}$ defect in a long bone. Autogenous graft is preferred to allograft method, considering the immunologic, infectious, and religious reasons. ${ }^{23}$ Hemi-articular and total elbow allografts are options for reconstruction following tumor excision, however this exposes patients to a higher risk of complication, and only employed as limb salvage procedures if total elbow replacement failed. Wide resection and non-vascularized fibular graft procedure may result in good functional outcome and lower risk for recurrence. Elbow reconstruction with non-vascularized fibular graft is a viable, as it is correlated good pain relief and functional improvement.

Most of the authors have reported different success rates with nonvascularized fibular graft. Dell et al found no significant difference between non-vascularized and vascularized graft in the consolidation time or union incidence. ${ }^{26}$ The use of non-vascularized technique has resulted in encouraging results. It resulted a satisfactory functional and cosmetic results and is relatively low on major complications ${ }^{27}$ At the donor site of proximal fibula, there was no reported instability of the knee from the study by Saikia et al. in 24 GCT patients following bloc resection and autogenous NVFG reconstruction. From this study, there were two cases of peroneal nerve palsy but they healed spontaneously at sixth and tenth weeks. ${ }^{28}$ In the contrary, the complications rate in vascularized graft have been reported between 4-12\%. Vascularized fibular grafting has been reported to enhance healing process but the operation time often reaches 12-14 hours and requires sacrificing two major vessels. Meticulous surgical procedure and prolonged operating time may cease the effectifity. ${ }^{26}$

As this tumor is relatively rare, there have been only few published studies evaluating results of non-vascularized fibular autograft for proximal radial resection and reconstruction..$^{24,29}$ The resection and reconstruction of the proximal radius is very rarely indicated, and thus, the indications of the various reconstructive options and their comparative strengths and weaknesses have not been thoroughly investigated. In spite of advantages using non non-vascularized fibularized graft after tumor resection, Seok W et all and Saini R et all reported several complications performing this method for distal radial giant cell tumor resection including wrist subluxation, nonunion, delayed union, fracture at the plate site, and superficial infection. ${ }^{26,29}$

In the follow up of the patients, we measured patients' elbow 
function using American Shoulder and Elbow Surgeons-Elbow (ASES-E) as a standardized elbow evaluation developed by the Research Committee of the American Shoulder and Elbow Surgeons (ASES) (Table 2). The questionnaire consists of two parts: a patient questionnaire and physician questionnaire to record elbow impairment. This form is divided into three main sections: pain, function and satisfaction. The first section contains VAS for pain evaluation. The second section contains for assessment of both arms' functions. The responses are scored on a four-point ordinal scale from 0 (unable to do); to 3 (no difficulties). The third section assesses of surgery outcome, scored on a scale from 0 to 10 . And the section on physician assessment consists of four parts: motion (measurement of records active flexion, extension, pronation and supination), stability (evaluation for valgus, varus and posterolateral rotatory instability), strength (flexion, extension, pronation and supination) and physical findings (enclose the evaluation of tenderness). Active range of motion is measured with a standard goniometer. Stability test is graded on a four-point scale: $0=$ no instability; $1=$ mild laxity with good endpoint; $2=$ moderate laxity with no endpoint; $3=$ gross instability. Strength is rated in six-point scale: $0=$ no contraction; $1=$ flicker; $2=$ movement with gravity eliminated; $3=$ movement against gravity; $4=$ movement with some resistance; $5=$ normal power. Grip strength is also recorded. The physical findings graded on a four-point scale from 0 (none) to 3 (severe) and other signs (such as pain, scars and atrophy) are reported only as present or absent $(\mathrm{Y} / \mathrm{N})$.

All three patients experienced no pain, no difficulty during daily activities, and were satisfied with the result of the surgery. We did examination of the elbow and found there were increased postoperative range of motion, stability, and strength of the elbow in all patients.

\section{Conclusion}

In summary, this was a case series of a Giant cell tumor at the elbow regions. The biopsy and MRI provided excellent depiction in suggesting the diagnosis of GCT. We performed wide excision and reconstruction with non vascularized fibular graft. The procedure provided excellent local control and good aesthetic and functional outcomes.

\section{Acknowledgments}

None.

\section{Funding}

None.

\section{Conflict of interest}

There is no conflict of interest.

\section{References}

1. Eckardt JJ GT. Giant cell tumor of bone. Clin Orthop Relat Res. 1986;204(2):45-58.

2. Mc Grath PJ. Giant-cell tumour of bone: an analysis of fifty-two cases. $J$ Bone Jt Surg Br. 1972;54(2):216-29.

3. Siebenrock KA, Unni KK RM. Giant-cell tumour of bone metastasising to the lungs. A long-term follow-up. J Bone Jt Surg Br. 1998;80(1):4347.

4. Mendenhall WM, Zlotecki RA, Scarborough MT, et al. Giant cell tumor of bone. Am J Clin Oncol. 2006;29(1):96-99.

5. Hoeffel JC, Galloy MA, Grignon Y, et al. Giant cell tumor of bone in children and adolescents. Rev Rhum Engl Ed. 1996;63(9):618-623.

6. Sanjay BK, Frassica FJ, Frassica DA, et al. Treatment of giant-cell tumor of the pelvis. J Bone Jt Surg Am. 1993;75(10):1466-1475.

7. Jeys LM, Suneja R, Chami G, et al. Impending fractures in giant cell tumours of the distal femur: incidence and outcome. Int Orthop. 2006;30(2):135-138.

8. Lewis VO, Wei A, Mendoza T, et al. Argon beam coagulation as an adjuvant for local control of giant cell tumor. Clin Orthop Relat Res. 2007;454(1):192-197.

9. Rock M. Curettage of giant cell tumor of bone. Factors influencing local recurrences and metastasis. Chir Organi Mov. 1990;75(1 Suppl):204-205.

10. Miller G, Bettelli G, Fabbri N CR. Curettage of giant cell tumor of bone. Introduction--material and methods. Chir Organi Mov. 1990;75(1 Suppl):203.

11. Campanacci M, Baldini N, Boriani S SA. Giant-cell tumor of bone. $J$ Bone Jt Surg Am. 1987;69(1):106-114.

12. Liu HS WJ. Treatment of giant cell tumor of bone:a comparison of local curettage and wide resection. Chang Yi Xue Za Zhi. 1998;21(1):37-43.

13. Khan MT, Gray JM, Carter SR, et al. Management of the giant-cell tumours of the distal radius. Ann R Coll Surg Engl. 2004;86(1):18-24.

14. Chen TH, Su YP CW. Giant cell tumors of the knee: subchondral bone integrity affects the outcome. Int Orthop. 2005;29(1):30-34.

15. Trieb K, Bitzan P, Lang S, et al. Recurrence of curetted and bone-grafted giant-cell tumours with and without adjuvant phenol. Ther J Surg Oncol. 2001;27(2):200-202.

16. Nelson DA, Barker ME, Hamlin HB. Thermal effects of acrylic cementation at bone tumour sites. Int J Hyperth. 1997;13(3):287-306.

17. Nicholson NC, Ramp WK, Kneisl JS KK. Hydrogen peroxide inhibits giant cell tumor and osteoblast metabolism in vitro. Clin Orthop Relat Res. 1998;347(3):250-260.

18. Malone S, O'Sullivan B, Catton C, et al. Long-term follow-up of efficacy and safety of megavoltage radiotherapy in high-risk giant cell tumors of bone. Int J Radiat Oncol Biol Phys. 1995;33(3):689-694.

19. Zhen W, Yaotian H, Songjian L, Ge L QW. Giant-cell tumour of bone. The long-term results of treatment by curettage and bone graft. $J$ Bone $J t$ Surg Br. 2004;86(2):212-216.

20. Prosser GH, Baloch KG, Tillman RM, et al. Does curettage without adjuvant therapy provide low recurrence rates in giant-cell tumors of bone? Clin Orthop Relat Res. 2005;(435):211-218.

21. Surgeons AA of O. Giant cell tumor of bone.

22. American Academy of Orthopedic Surgeons. Giant cell tumor of bone. 2007.

23. Nishida J Shimamura T. Methods of reconstruction for bone defect after tumor excision: a review of alternatives. Med Sci Monit. 2008;14(8):RA107-113.

24. Longo UG, Franceschi F, Loppini M, et al. Rating systems for evaluation of the elbow. Br Med Bull. 2008;87:131-161.

25. Lenze U, Kasal S, Hefti F, et al. Non-vascularised fibula grafts for reconstruction of segmental and hemicortical bone defects following meta- / diaphyseal tumour resection at the extremities. BMC Musculoskelet Disord. 2017:18(1):289. 
26. Saini R, Bali K, Bachhal V, et al. En bloc excision and autogenous fibular reconstruction for aggressive giant cell tumor of distal radius : a report of 12 cases and review of literature. J Orthop Surg Res. 2011.

27. Dahuja A, Kaur R, Bhatty S, et al. Giant-cell tumour of proximal radius in a 50-year-old female with wrist drop : a rare case report. Strateg Trauma Limb Reconstr. 2017;12(3):193-196.
28. Saikia K, Borgohain M, Bhuyan S. Resection-reconstruction arthroplasty for giant cell tumor of distal radius. Indian J Orthop. 2010;44(3):327332 .

29. Seok W, Wan S, Cho H. Composite reconstruction after proximal radial giant cell tumor resection. Arch Orthop Trauma Surg. 2011:627-630. 